\title{
Economia criativa, desenvolvimento e sustentabilidade: o caso do Rio de Janeiro
}

\author{
Creative economy, development and sustainability: the case of Rio de Janeiro
}

Diego Santos Vieira de Jesus ${ }^{1}$

\begin{abstract}
Resumo
O objetivo do artigo é examinar como a sustentabilidade oferece um dos pilares fundamentais ao desenvolvimento da economia criativa no Rio de Janeiro. Com base no referencial teórico de Richard Florida e Ana Carla Reis, o argumento central aponta que a economia criativa no Rio de Janeiro promove uma dinâmica de valorização, proteção e promoção da diversidade das expressões culturais como forma de garantir a sua originalidade. Para que se garantam a sua força e o seu potencial de crescimento, o poder público e os agentes sociais precisam assegurar sustentabilidade social, cultural, ambiental e econômica em condições semelhantes de escolha para as gerações futuras. Ademais, assumir a economia criativa como vetor de desenvolvimento seria assumi-la como um processo cultural gerador de inovação e promotora da inclusão produtiva da população, priorizando aqueles que se encontravam em situação de vulnerabilidade social, por meio da formação e da qualificação profissional e da geração de oportunidades de trabalho e de renda. O desenvolvimento de políticas coerentes para a inovação cultural - que tem como sustentáculo a criatividade, entre outros componentes - é algo crítico para que no longo prazo se alcance um desenvolvimento economicamente sustentável.
\end{abstract}

Palavras-chave: Economia criativa. Sustentabilidade. Rio de Janeiro.

\begin{abstract}
The objective of the article is to examine how sustainability offers one of the fundamental pillars for the development of the creative economy in Rio de Janeiro. Based on the theoretical references of Richard Florida and Ana Carla Reis, the central argument points out that the creative economy in Rio de Janeiro promotes a dynamics of valorization, protection and promotion of the diversity of cultural expressions as a way of guaranteeing their originality. In order to guarantee their strength and growth potential, public authorities and social agents need to ensure social, cultural, environmental and economic sustainability under similar conditions of choice for future generations. In addition, assuming the creative economy as a vector of development would assume it as a cultural process that generates innovation and promotes the productive inclusion of the population. It prioritizes those who were in a situation of social vulnerability, through training and professional qualification and generation of job and income opportunities. The development of coherent policies for cultural innovation - which has as its foundation creativity, among other components - is critical for long-term economic development.
\end{abstract}

Keywords: Creative economy. Sustainability. Rio de Janeiro.

\footnotetext{
${ }^{1}$ Professor e pesquisador do Programa de Mestrado Profissional em Gestão da Economia Criativa (MPGEC) da Escola Superior de Propaganda e Marketing do Rio de Janeiro (ESPM-Rio). E-mail: dvieira@espm.br.
} 


\section{Introdução}

A economia criativa engloba setores baseados no talento ou na habilidade individual, como publicidade, arquitetura, artesanato, design, moda, cinema, softwares interativos para lazer, música, artes performáticas, mercado editorial, rádio, TV e museus. O fortalecimento desses setores ocorre em um contexto de ampliação de necessidades de ordem estética e intelectual pelos indivíduos e de emergência da sociedade do conhecimento, na qual uma economia baseada no uso intensivo de capital e trabalho cede gradualmente espaço para outra baseada nos recursos intelectuais e na troca de conhecimentos (BENDASSOLLI et al., 2009, p. 11; MIGUEZ, 2007, p. 96-97). Além de serem imprescindíveis para a competitividade das empresas, as particularidades culturais na base dos setores criativos podem ser mobilizadas por governos e atores econômicos e sociais como recursos territoriais que estimulam competências pela diferenciação e geram emprego e renda (JESUS; KAMLOT, 2016, p. 16-18). Em uma "cidade criativa", a criatividade se relaciona não apenas à atração de talentos ou ao fortalecimento do potencial inovador de empresas, mas à aplicação de inovações sociais em áreas como saúde, serviços sociais, governança e meio ambiente (CHANTELOT et al., 2011, p. 7-9).

A sustentabilidade está na base de estratégias voltadas para o desenvolvimento local, regional e nacional focadas na economia criativa, o que implica trazer maior transparência aos processos sociais, compreender a complexidade da cultura, entender o conceito de desenvolvimento sob um prisma cultural, político e socioeconômico e engajar o setor privado como promotor de responsabilidade social e ambiental e parceiro no desenvolvimento de produtos e serviços e na consecução de programas sustentáveis (REIS, 2006, p. 163-172). Obras estratégicas - como aquelas relacionadas a competições esportivas ou eventos culturais de grande porte - podem conduzir a esforços de captação de recursos entre diferentes níveis de governo e de fortalecimento dos negócios locais a partir da ressignificação de espaços em um contexto de desenvolvimento sustentável (MOURA, 2007, p. 349; REIS, 2011, p. 1013). Essa concepção de desenvolvimento conduz a uma necessidade de se repensarem formas de exploração de recursos, tecnologia e marcos institucionais, de se superarem déficits sociais nas necessidades básicas e de se alterarem padrões de consumo. Para que ações e práticas possam ser executadas, mostra-se fundamental a existência de interlocutores e participantes sociais por meio de práticas educativas e do diálogo, o que fortalece a ideia de corresponsabilização e de constituição de valores éticos (JACOBI, 1999, p. 175-179; ROMEIRO, 2001). No que diz respeito especificamente à 
economia criativa, ainda que seus defensores apontem a sustentabilidade como um de seus pilares, os imperativos econômicos do "cosmopolitismo competitivo" podem trazer fórmulas estéreis que ignoram especificidades locais (MILES, 2014, p. 128-129) e, assim, manter um modelo predatório que vai radicalmente contra os princípios ligados à ideia de desenvolvimento sustentável.

A economia criativa assumiu particular importância como vetor de desenvolvimento na cidade do Rio de Janeiro, que concentra em torno de $80 \%$ da renda e do emprego da economia criativa no estado (APRIGIO, 2015, p. 60). O apoio à economia criativa pela prefeitura é voltado para o estímulo à produção, comercialização, infraestrutura e treinamento nas atividades criativas, particularmente em setores como cinema e TV. O conteúdo simbólico e intangível alto da cidade também aumentou o valor agregado das exportações de moda (WORLD CITIES CULTURE FORUM, 2015). Eventos culturais de grande porte, como os desfiles das escolas de samba e festivais como o Rock in Rio, oferecem vitrines internacionais para a cidade, bem como seus bairros e atrações turísticas. As parcerias com os governos federal e estadual criaram as condições de possibilidade para a realização de eventos como os Jogos Olímpicos e Paraolímpicos de 2016 na expectativa de abertura de oportunidades para setores e profissionais criativos na cidade, captando investimentos e oferecendo suporte em inteligência de mercado (APRIGIO, 2015, p. 49-50, 80-83), bem como as iniciativas de revitalização de setores da cidade (MERCHER, 2013, p. 105). Empreendimentos imobiliários e empresas de entretenimento mobilizaram as identidades locais para se estabelecerem em áreas da cidade potencialmente lucrativas, como a região portuária, onde grandes equipamentos culturais foram construídos tendo em vista a promoção de sustentabilidade (WANIS, 2013). A importância da economia criativa para a cidade foi fortalecida com o recebimento do título de Patrimônio Mundial da Humanidade pela Unesco.

Tendo isso em vista, o objetivo da pesquisa é examinar como a sustentabilidade oferece um dos pilares fundamentais ao desenvolvimento da economia criativa na cidade do Rio de Janeiro. Com base no referencial teórico de Richard Florida e Ana Carla Reis, o argumento central aponta que a economia criativa no Rio de Janeiro promove uma dinâmica de valorização, proteção e promoção da diversidade das expressões culturais como forma de garantir a sua originalidade. Para que se garantam a sua força e o seu potencial de crescimento, o poder público e os agentes sociais precisam assegurar sustentabilidade social, cultural, ambiental e econômica em condições semelhantes de escolha para as gerações futuras. Ademais, assumir a economia criativa como vetor de desenvolvimento seria assumi-la como um processo cultural gerador de inovação e promotor da inclusão produtiva da população, priorizando aqueles que se encontravam em situação de vulnerabilidade social, por meio da formação e da qualificação profissional 
e da geração de oportunidades de trabalho e de renda. O desenvolvimento de políticas coerentes para a inovação cultural - que tem como sustentáculo a criatividade, entre outros componentes - é algo crítico para que no longo prazo se alcance um desenvolvimento economicamente sustentável.

\section{Referencial teórico}

Diante da necessidade de enfrentamento da crise ecológica desde a década de 1970, a ideia de "ecodesenvolvimento" desenvolvida por Ignacy Sachs (1993) era baseada nas dimensões de sustentabilidade social, econômica, ecológica, espacial e cultural num contexto de ações e práticas voltadas para a compatibilização da melhoria da qualidade de vida e da preservação ambiental e pautadas em iniciativas locais para a redução da dependência técnica e cultural em relação a Estados desenvolvidos e a harmonização entre processos ambientais e socioeconômicos. Diante da crise econômica da década de 1980, houve um esvaziamento da noção de ecodesenvolvimento em termos de políticas, mas não no debate intelectual em torno do agravamento da degradação ambiental e da ampliação das desigualdades socioeconômicas em todo o mundo. O questionamento dos paradigmas de desenvolvimento existentes ficou claro no Relatório Brundtland de 1987, que trabalhava a concepção de "desenvolvimento sustentável", clamava por uma postura ética com relação às temáticas ambientais e reforçava a conexão entre economia, tecnologia, sociedade e política. O conceito de "desenvolvimento sustentável" - que ampliava o foco da noção de ecodesenvolvimento para uma dimensão globalizante em termos das causas e das soluções para as questões ambientais - e a lista de ações indicadas no relatório serviram como marcos para a Conferência das Nações Unidas sobre o Meio Ambiente e o Desenvolvimento de 1992, a Rio 92, na busca de ações concretas para a conciliação entre as atividades econômicas e a garantia de um futuro sustentável, baseadas num tripé de eficiência econômica, justiça social e prudência ecológica. Ainda que o conceito enfrente uma série de restrições tecnológicas, culturais, econômicas e socioambientais para sua plena aplicação prática, ele tem permitido a integração gradual entre meio ambiente e desenvolvimento e a articulação com outros discursos que repensam paradigmas de desenvolvimento, como aqueles ligados à economia criativa (JACOBI, 1999, p. 175-179). Valores e políticas relacionados ao desenvolvimento sustentável vêm sendo gradualmente internalizados por movimentos sociais e governos. As empresas aderiram inicialmente de fora para dentro como forma de responder a críticas de entidades governamentais e grupos da sociedade civil que as responsabilizavam pela destruição do meio ambiente. Mais recentemente, a adesão empresarial ocorre pelo reconhecimento 
do desenvolvimento sustentável como fator de competitividade e fonte de diferenciação ou qualificação (BARBIERI et al., 2010, p. 147-149).

Como aponta Ana Carla Reis (2006, p. 112-129), políticas públicas relacionadas à economia criativa visam estimular a diversidade de culturas para a participação nos fluxos de ideias e comércio de produtos e serviços, em particular as expressões culturais minoritárias para que não sejam sufocadas pelas majoritárias, garantindo-se sua sustentabilidade econômica. A atuação da economia criativa como agente de recuperação e regeneração urbanas traz benefícios que vão além da geração de impostos, empregos e comércio e incorporam a elevação da autoestima local (REIS, 2006, p. 112-129). Porém, tais esforços exigem ações para a movimentação econômica e a dinamização de bens simbólicos ou materiais que mantenham a sustentabilidade econômica das suas iniciativas. A organização de articulações em polos criativos e entre eles e a formação de redes e cadeias de produção, circulação, uso, troca de experiências e cooperação entre os participantes do ambiente criativo trazem à tona a sinergia na busca do desenvolvimento sustentável local, bem como a agregação de iniciativas e empreendimentos e grupos informais com vocação produtiva semelhante, a valorização do empreendedorismo para o desenvolvimento pessoal autônomo e o surgimento de novas formas de governança que envolvam a participação dos cidadãos. A inserção da responsabilidade ecológica e ambiental na base de trabalho pode acompanhar esses desenvolvimentos (CLOSS et al., 2014, p. 7-8).

Richard Florida (2002) coloca que a criatividade é uma habilidade crucial em uma economia baseada no conhecimento e que a classe criativa detém a chave para o crescimento econômico e a competitividade. Tal classe é caracterizada por três fatores (os três Ts): a tecnologia - o conhecimento e a capacidade de dominar as infraestruturas tecnológicas onde vão fluir, circular e interagir os produtos criativos -; o talento - o individual e o potenciado pela convivência dos talentos; - e a tolerância em relação às diversidades. Nessa perspectiva, pessoas criativas e novas ideias precisam de um ambiente sustentável tolerante e aberto à diversidade a fim de desenvolver, difundir, implementar e melhorar ideias. O simples acúmulo de pessoas criativas ou talentosas representa uma condição necessária, mas não suficiente para que uma cidade criativa possa se desenvolver. Cidades podem ser consideradas um conjunto de conjuntos criativos: por um lado, as indústrias criativas produzem e oferecem resultados criativos ao mercado; por outro, pessoas criativas interagem fora da esfera orientada pelo mercado e exploram, geram e difundem ideias, inclusive aquelas associadas à sustentabilidade. Dessa forma, cabe às cidades criativas gerenciar o trânsito de ideias de pessoas talentosas para ideias exploráveis pelas indústrias criativas. 
Dentre os tipos de intervenção prática que podem ser englobados nas estratégias de uma cidade criativa para promover e apoiar empreendimentos criativos sustentáveis em localidades específicas, cabe citar as estratégias de propriedade; desenvolvimento de negócios, aconselhamento e construção de redes; esquemas de auxílios e empréstimos diretos para empreendedores e negócios criativos; iniciativas fiscais; infraestrutura física e de tecnologia de informação; e infraestrutura branda. Muitas dessas intervenções são típicas de iniciativas genéricas de apoio a negócios ao oferecer local de trabalho e treinamento, assistência, networking e empréstimos, práticas de gestão de negócios, acesso a eventos comerciais e novas tecnologias. Algumas são específicas da economia criativa, tais como o levantamento de verbas para o investimento na infraestrutura artística. Muitas iniciativas para a economia criativa são dirigidas para startups, pequenas e médias empresas, e quando as necessidades específicas das indústrias criativas são destacadas, tendem a enfatizar as peculiaridades do processo criativo e o desenvolvimento de habilidades para os negócios entre os praticantes (FOORD, 2008, p. 97-98).

A busca de políticas para a inovação cultural é fundamental para que se atinja desenvolvimento economicamente sustentável, o que comprova o papel fundamental da educação na geração de conhecimento e inovação (ARAYA, 2010). O estímulo a competências criativas não se restringe à dimensão técnica, de forma a também abarcar atitudes e posturas empreendedoras, habilidades sociais e de comunicação, compreensão de dinâmicas socioculturais e de mercado, capacidade de articulação e sustentabilidade (SEC, 2012, p. 37). A mudança da atuação das empresas para a redução dos impactos socioambientais exige uma nova forma de lidar com a inovação, de forma a se alcançar o desenvolvimento sustentável. Empresas que inserem novidades de qualquer tipo com autonomia, intencionalidade e proatividade devem procurar eficiência econômica, bem como o respeito à capacidade de suporte ambiental e a inclusão social de grupos vulneráveis. Tal postura abarca preocupação com impactos sociais das inovações - como desemprego, exclusão social ou pobreza -, bem como com o uso de recursos naturais e a geração de vantagens competitivas em mercados em que atuam. A inovação sustentável pressupõe a produção, a assimilação ou a exploração de produtos, processos produtivos, métodos de gestão ou negócios novos ou melhorados que tragam benefícios econômicos, sociais e ambientais (BARBIERI et al., 2010, p. 147-151).

Nesse sentido, a economia criativa coloca-se num debate não necessariamente do “desenvolvimento pelo desenvolvimento", mas numa discussão sobre caminhos e oportunidades para se pensarem não só em alternativas de desenvolvimento, mas de alternativas ao desenvolvimento, tal qual entendido de forma linear e ambientalmente agressiva na era industrial. Argumenta-se neste artigo que a 
economia criativa tem o potencial para que se desenvolvam formas diversas de se conceber o meio ambiente, não o tratando apenas como um simples repositório de matérias-primas. Tal economia pode despertar a necessidade de se retomar o que Arturo Escobar (2014) coloca como a "intimidade com a Terra", que permitiria aos seres humanos verem a eles mesmos como partes integrais do universo. O "sentipensamento" definido pelo autor aponta que o conhecimento abstrato pode até ajudar a compreender a natureza, mas não seria suficiente para compreender o fluxo incessante de vida do qual todos somos parte. Ao valorizar os aspectos culturais e sua íntima relação com o ambiente em que esses indivíduos estão inseridos, a economia criativa permitiria ressituar o humano no fluxo da vida ao reconhecer as múltiplas diferenças socioculturais que compõem o universo e pensar o desenvolvimento em termos que, como coloca Escobar (2014), superam sua equiparação com a concepção de "progresso", a partir da qual o consumo individual e a competitividade de mercado se converteram em normas.

\section{Método}

O método aplicado nesta pesquisa é o qualitativo, que, segundo Ragin (1994, p. 81-102), permite o exame em profundidade e a investigação de fenômenos significativos histórica e culturalmente ao exigir maior atenção ao detalhe. A partir de uma coleta de dados feita por pesquisa bibliográfica, foi realizado um estudo de caso, que, segundo Bennett (2004, p. 19-21), refere-se à análise interna de situações específicas e às comparações entre um pequeno número de casos e lidam com aspectos bem definidos de um acontecimento histórico selecionado para investigação. Embora os estudos de caso permitam o alcance de altos níveis de validação e o uso de generalizações contingentes a fim de modelar relações complexas, eles têm limitações potenciais, como a dificuldade de se controlarem perfeitamente as comparações entre os casos, além das inerentes, como a inabilidade relativa de fazer julgamento sobre a frequência ou a representatividade de casos particulares e a sua fraca capacidade de estimar o peso causal das variáveis. Ainda assim, é possível buscar a geração de novas hipóteses indutivamente e o teste de teorias que visam explicar apuradamente processos e resultados de casos particulares (BENNETT, 2004, p. 19-21).

Neste artigo, o caso selecionado para o estudo da sustentabilidade como pilar do desenvolvimento é a cidade do Rio de Janeiro, tendo em vista que, na implementação de uma estratégia de estímulo a setores criativos, as políticas públicas na cidade foram desenvolvidas em meio a desafios como a maior 
mobilidade turística, a necessidade de ressignificação de espaços e dinâmicas, a valorização da cultura também como setor econômico e condição imprescindível para a formação de ambientes criativos, os quais têm claras implicações socioeconômicas e ambientais. O estudo de caso permite, nesta situação, entender as especificidades dos processos a partir dos quais a sustentabilidade foi sendo colocada como elemento fundamental na concepção de desenvolvimento almejada pelos agentes políticos e sociais na cidade diante dos desafios postos.

Para a análise interna do caso selecionado, foi feito o rastreamento do processo (process tracing), que permite verificar se o caminho entre uma causa hipotética e o efeito observado comportou-se como previsto pelas teorias sob investigação (BENNETT, 2004, p. 22-24). Van Evera (1997, p. 64-67) ressalta que, no rastreamento do processo, o investigador explora a cadeia de eventos ou de processos de formulação da decisão pela qual as condições iniciais do caso são traduzidas em resultados. A ligação causa-efeito é revelada e dividida em passos menores. O investigador busca, então, a evidência observável de cada passo. Ela pode ser buscada na sequência e na estrutura de eventos, cujos dados foram coletados a partir da pesquisa bibliográfica já indicada.

$\mathrm{Na}$ situação específica deste estudo, pretendeu-se rastrear a cadeia de eventos pelas quais a condição inicial de crítica a uma noção de desenvolvimento atrelada à ideia de crescimento econômico em nível internacional resultou na adoção de uma agenda de desenvolvimento focada na economia criativa e na sustentabilidade e, a partir daí, na conjugação da economia criativa com a noção de desenvolvimento sustentável como uma estratégia de desenvolvimento para o Rio de Janeiro, que enfatiza não apenas os projetos de maior magnitude, mas também o apoio a micro e pequenos empreendimentos criativos. Tais empreendimentos contribuem para a disseminação de práticas sustentáveis e, num contexto mais amplo, para uma mudança de pensamento em relação à própria natureza, concebida meramente como um reservatório de recursos numa noção mais tradicional de progresso. Exemplos desses empreendimentos potencialmente transformadores serão apresentados na próxima seção.

\section{Análise dos resultados}

Em nível mundial, a crítica a uma ideia de desenvolvimento colocada como sinônimo de crescimento econômico ficou clara em 1998, quando a Conferência Intergovernamental sobre Políticas 
Culturais para o Desenvolvimento sinalizou a relação entre cultura e desenvolvimento sustentável e recomendou a inserção da política cultural como elemento central propulsor do desenvolvimento. A Comissão Mundial de Cultura e Desenvolvimento, criada pela Organização das Nações Unidas para a Educação, a Ciência e a Cultura (Unesco), concebeu a cultura como a base social para as ações humanas, como conservação do meio ambiente e proteção das instituições civis. A noção de desenvolvimento socioeconômico considerava cada vez mais o contexto cultural e ambiental em que a sociedade se coloca (AGUIAR, 2015, p. 981-984). Seguindo essa linha, o Ministério da Cultura brasileiro veio buscando elaborar uma agenda abrangente e transversal de desenvolvimento, caracterizada pela economia criativa e atenta à sustentabilidade. Em 2010, foi implantada no Ministério a Secretaria de Economia Criativa (SEC), voltada para a formulação e implementação de políticas públicas de desenvolvimento local e regional com o apoio ao micro e pequeno empreendedor nos setores criativos. A concepção da cultura a partir de dimensões simbólica, cidadã e econômica visava à valorização, proteção e promoção da diversidade das expressões culturais nacionais como meios de garantir sua originalidade e força e garantir sustentabilidade social, cultural, ambiental e econômica para as gerações futuras a partir de inovação e inclusão produtiva (LEITÃO, 2013, p. 46-47; SILVA, 2012, p. 118-119). Durante o governo de Luiz Inácio Lula da Silva (2003-2010), o governo federal procurou estimular medidas que conciliassem crescimento econômico e inclusão social, mas o reconhecimento legal da SEC deu-se somente em 2012, no governo de Dilma Rousseff (2011-2014). Entretanto, as missões grandiosas de promoção do desenvolvimento excediam as capacidades operacionais do Ministério da Cultura (DUQUE, 2015, p. 496-497; MARCHI, 2014, p. 195-196, 205-206). Para que se criasse uma ambiência favorável ao desenvolvimento da economia criativa, seria fundamental o estímulo a processos de institucionalização de territórios criativos e à articulação e à elaboração de propostas de adequação de marcos legais (SEC, 2012, p. 22-23, 34-38, 42-43), mas que jamais vieram a ser plenamente desenvolvidos. A primeira gestão da SEC trouxe resultados práticos muito pontuais e em 2015, a Secretaria foi extinta (MARQUES, 2015).

Apesar dos obstáculos ao desenvolvimento da economia criativa em nível nacional, a cultura aparece como uma plataforma de desenvolvimento local no Rio de Janeiro ao atenuar as tensões sociais e funcionar como ferramenta de transformação urbana a partir de projetos criativos liderados pela prefeitura (APRIGIO, 2015, p. 60). Essa dinâmica favoreceu a vinda de profissionais criativos para a cidade e robusteceu as capacidades de empreendimentos criativos, como a Jequitibá - empresa que trabalha na conservação e no restauro de bens móveis e imóveis - e o Projeto Subsolo, que atua na elaboração, produção e gerenciamento de projetos e produtos inovadores relacionados às artes visuais e 
cultura contemporânea e busca criar novas possibilidades de conexão entre arte, sustentabilidade e desenvolvimento local. Essas empresas são exemplos de empreendimentos no campo da economia criativa que receberam o apoio da Incubadora Rio Criativo, que proporciona um ecossistema completo de estímulo, de interação multissetorial e de compartilhamento de ideias e de ferramentas, estimulando o surgimento de novas parcerias, colaborações, geração de negócios e capacitação (RIO CRIATIVO, s.d.).

Ademais, entidades privadas como o Sebrae (Serviço Brasileiro de Apoio às Micro e Pequenas Empresas) visam à promoção da competitividade e do desenvolvimento sustentável dos empreendimentos de micro e pequeno porte, além de buscarem estimular o empreendedorismo e acelerar a formalização da economia por meio de parcerias com os setores público e privado, programas de capacitação e acesso ao crédito e à inovação (SEBRAE, 2012, p. 7-8). Numa perspectiva mais ampla para além dos aspectos econômicos, a ênfase na promoção do desenvolvimento sustentável em inúmeras iniciativas envolvendo setores criativos na cidade busca estimular no cidadão a geração de responsabilidades éticas - que permitem o questionamento sobre modelos predatórios de desenvolvimento - e a reconsideração de aspectos relacionados ao desenvolvimento de equidade e justiça social, com base no exercício de cidadania e na alteração de valores e princípios individuais e coletivos (JACOBI, p. 179-180).

Uma cidade criativa pretende também se colocar como uma cidade sustentável, cujos governos devem atentar para as necessidades presentes e as bases para futuras gerações implementando programas de redução de emissão de gases poluentes e de despoluição dos rios e lagoas, bem como iniciativas para que se busquem eficiência energética, melhor gestão da água, melhoria da mobilidade urbana e urbanização de favelas, por exemplo (FREITAS, 2013). Entretanto, o Rio de Janeiro pode apresentar desafios ao pleno desenvolvimento de setores criativos e sustentáveis, como a gentrificação e o reforço às assimetrias socioeconômicas. A atração de mais pessoas para essas cidades pode vir acompanhada do aumento de preços, da maior competição por empregos e da especulação imobiliária. Essa dinâmica pode conduzir à falta de incentivos e subsídios ao emprego e de condições dignas de moradia para a população local (REIS; URANI, 2011, p. 34-37), o que afeta diretamente o meio ambiente, com a ocupação irregular do solo em favelas e comunidades carentes. O Rio de Janeiro é vulnerável às mudanças do clima, o que se vê em enchentes que causam inundações e deslizamentos de terras, nas ondas de calor e nos impactos sobre a infraestrutura, como desabamentos e danos à rede de drenagem, às estradas e à rede elétrica, de gás, de telefonia e digital. Tais problemas causam transtornos no abastecimento e nos serviços da cidade 
e trazem riscos à segurança e saúde públicas. Para a solução dessas questões, seriam necessárias novas normas de ocupação do solo, bem como a implantação de redes elétricas inteligentes e redes digitais resilientes e a melhoria dos sistemas de alerta, prontidão e evacuação de locais vulneráveis. Faz-se necessária também a redução de emissões de gases estufa em face não somente de seus benefícios ambientais, mas em termos da qualidade de vida dos cidadãos. Além da geração de empregos em projetos de reflorestamento e arborização e em obras públicas de transportes sobre trilhos (trens, metrô e VLTs), ciclovias e corredores de ônibus articulados, haverá uma demanda adicional em termos técnicos por profissionais de setores criativos - como arquitetos, designers e profissionais que possam planejar e operar aspectos das transformações urbanísticas, como a promoção da "arquitetura verde" - e a criação de oportunidades de negócios produtivos e dinâmicos em âmbito empresarial. Essas inciativas devem vir acompanhadas de mudanças na tributação e intensificação da fiscalização municipal (RAPS, 2016, p. 47).

Entretanto, o atual contexto de crise político-econômica no Brasil e no estado do Rio de Janeiro coincide com o estancamento de investimentos públicos e privados após a realização dos Jogos Olímpicos de 2016, a queda da arrecadação por conta da recessão e a crise motivada pela excessiva dependência criada em relação à indústria do petróleo. No contexto pós-olímpico, é visível também a crise do setor imobiliário, com grande sobreoferta de imóveis residenciais e comerciais, bem como no setor hoteleiro. Porém, tal crise traz a oportunidade para que se desenvolvam novamente as bases de um modelo alternativo de desenvolvimento, que tenha a sustentabilidade como pilar e a economia criativa como seu principal motor. Isso pode ocorrer, por exemplo, com o estímulo ao setor criativo do turismo sustentável, aprimorando-se sua capacidade de atração e se estimulando permanência e frequência maiores. O legado olímpico poderia ser melhor aproveitado com calendários alternativos de eventos temáticos e programas de capacitação poderiam ampliar a qualidade de atendimento e a hospitalidade carioca em setores como hotelaria e gastronomia. Áreas revitalizadas como a região portuária poderiam ser locais em que as indústrias da cultura e do entretenimento fossem mais exploradas. Para tanto, a eliminação dos obstáculos ao empreendedorismo - em especial da burocracia, da morosidade na concessão de alvarás e da simplificação das condições para regularização de atividades econômicas criativas informais - seria fundamental (RAPS, 2016, p. 8-9).

Ainda que o Rio de Janeiro seja dotado de inúmeras belezas naturais, grande parte dos moradores ainda observa que seus rios e lagoas servem apenas como depósitos de resíduos ou cenários de contemplação. Com o despejo de esgoto in natura nas águas e a multiplicação de comunidades em torno 
de lagoas - em especial na Zona Oeste -, a degradação ambiental avança na cidade. Melhorias ambientais prometidas com a realização dos megaeventos esportivos na cidade - como a despoluição da Baía de Guanabara - jamais se concretizaram (FREITAS, 2013). Tais questões tornam urgente o incremento aos meios e ao acesso aos conteúdos educativos e informacionais para a alteração do quadro de degradação ambiental e o desenvolvimento de iniciativas de corresponsabilização e compromisso com o meio ambiente. A potencialização de riscos ambientais dá-se também em temas referentes às opções de transporte, ao planejamento e uso do solo e ao acesso ao saneamento e à infraestrutura básica. Para que tais riscos sejam mitigados, faz-se necessária uma transformação paradigmática alicerçada em novos processos educacionais, para que se garanta o acesso dos diversos atores sociais às informações sobre serviços públicos - o que implica transformações institucionais para maior transparência na gestão urbana - e responsabilidade ambiental. O maior nível de conscientização ambiental deve acompanhar a geração de empregos com práticas sustentáveis, o que amplia a possibilidade de participação da população em processos decisórios e maior controle dos agentes responsáveis pela degradação ambiental (JACOBI, 1999, p. 180-182). Nesse sentido, a geração de empregos em setores criativos poderia acompanhar uma conscientização maior da sociedade carioca acerca das implicações do modelo de desenvolvimento baseado em uso intensivo de capital e trabalho.

Nesse processo, o setor produtivo local assume fundamental importância. Uma das mais expressivas iniciativas de engajamento e conscientização desse setor é a iniciativa Rio $+\mathrm{B}$, um esforço do Sistema B - versão latino-americana da ONG B Lab, mundialmente reconhecida pelo desenvolvimento de ferramentas de mensuração de impacto - com a prefeitura do Rio de Janeiro. Essa iniciativa procura engajar empresas locais em agendas de sustentabilidade urbana a partir de uma autoavaliação dessas companhias quanto a seu impacto socioambiental. A partir da verificação de sistemas de certificação internacional, as empresas cariocas - inclusive as ligadas à economia criativa podem mensurar como influenciam a sociedade ao redor. Ademais, a iniciativa pretende gerar um mapa do impacto socioambiental das empresas que operam no Rio de Janeiro e a articulação de novas políticas públicas setoriais, incluindo temas como economia criativa, criação de redes e sustentabilidade. Ela pretende apoiar a transição do setor privado para uma nova economia, nas quais as empresas demonstram uma preocupação maior com o impacto gerado pelo seu negócio na cidade (GIFE, 2016). 


\section{Conclusões}

A sustentabilidade como pilar da economia criativa instiga o desenvolvimento de parcerias entre agentes socioeconômicos e a utilização de novas tecnologias para a produção. Torna-se necessária a conscientização de gestores públicos e privados e da sociedade civil acerca do potencial dessa economia, sua estruturação em redes e o reconhecimento do valor econômico do intangível cultural (REIS, 2008, p. 47-48). Tais lideranças devem avaliar os resultados mais imediatos das estratégias adotadas quanto ao apoio ao empresariado, investimento em infraestrutura e planejamento urbano, e identificar as necessidades básicas frente à sustentabilidade de longo prazo, bem como melhores práticas das cidades com perfis semelhantes ao redor do mundo. Uma gestão mais profissional contando com pessoas qualificadas permite a defesa mais eficaz dos ativos ambientais e o desenvolvimento de meios inovadores em resposta a desafios urbanos (JOFFE, 2011, p. 67-68).

No âmbito de transformações sociais ainda mais profundas, o "sentipensamento" estimulado pela economia criativa poderia contribuir para o maior reconhecimento das diversidades socioculturais e um relacionamento mais íntimo entre os seres humanos e o ambiente, na linha colocada por Escobar (2014). Em uma dimensão mais prática, ela permite minimamente reconhecer, em bases próximas às sugeridas por Manfred Max-Neef, que o modelo atual de desenvolvimento é desastroso para o meio ambiente. Ao se confundir desenvolvimento com crescimento econômico nesse modelo, conduz-se a uma degradação ambiental cada vez mais intensa, que, a partir de determinado ponto, aponta para a queda na qualidade de vida das pessoas. Nesse sentido, cabe investir em projetos de desenvolvimento local que fortaleçam pequenos negócios sustentáveis e estimulem um contrato social entre governo, empresários e trabalhadores a fim não só de proteger a natureza, mas mudar a percepção que os seres humanos desenvolvem em relação a ela (MAX-NEEF, 1991).

\section{Referências}

AGUIAR, M. A. Políticas públicas de cultura e a promoção de desenvolvimento: questões teóricas. In: CALABRE, Lia; SIQUEIRA, Mauricio; LIMA, Deborah Rebello; ZIMBRÃO, Adélia (Orgs.). Anais do VI Seminário Internacional de Políticas Culturais. Rio de Janeiro: Fundação Casa de Rui Barbosa, 26-29 maio 2015, p. $977-988$. 
APRIGIO, A. E. A paradiplomacia e a atuação internacional de governos subnacionais. Dissertação - Mestrado em Relações Internacionais. Departamento de Relações Internacionais e Administração Pública, Escola de Economia e Gestão, Universidade do Minho, 2015.

ARAYA, D. Educational policy in the creative economy. In: PETERS, M. A. (Ed.). Education in the creative economy: knowledge and learning in the age of innovation. New York: Peter Lang, 2010.

BARBIERI, J. C.; VASCONCELOS, I.; ANDREASSI, T.; VASCONCELOS, F. C. Inovação e sustentabilidade: novos modelos e proposições. RAE, 50(2), 146-154, 2010.

BENDASSOLLI, P. F.; WOOD Jr., T.; KIRCHBAUM, C.; CUNHA, M. P. Indústrias criativas: definição, limites e possibilidades. RAE, 49(1), 10-18, 2009.

BENNETT, A. Case study methods: design, use, and comparative advantages. In: SPRINZ, D. F.; WOLINSKY-NAHMIAS, Y. (Eds.). Models, numbers, and cases: methods for studying international relations. Ann Arbor: The University of Michigan Press, 2004.

p. 19-55.

CHANTELOT, S.; PÉRÈS, S.; VIROL, S. From talent to creative cities: toward a conceptual framework. $51^{\text {st }}$ European Congress of the Regional Science Association International, New Challenges for European Regions and Urban Areas in a Globalised World, 2011.

CLOSS, L. Q.; OLIVEIRA, S. R.; AZEVEDO, P. R.; TIRELLI, C. Das cidades aos territórios criativos: um debate a partir das contribuições de Milton Santos. In: Anais do XXXVIII Encontro da Anpad. Rio de Janeiro, 13-17 set. 2014, p. 1-15.

DUQUE, F. S. Economia criativa: empreendimentos culturais. In: CALABRE, L.; SIQUEIRA, M.; LIMA, D. R.; ZIMBRÃO, A. (Orgs.). Anais do VI Seminário Internacional de Políticas Culturais. Rio de Janeiro: Fundação Casa de Rui Barbosa, 26-29 maio 2015, p. 487-497.

ESCOBAR, A. Sentipensar con la tierra. Nuevas lecturas sobre desarrollo, territorio y diferencia. Medellín: Unaula, 2014.

FOORD, J. Strategies for creative industries: an international review. Creative Industries Journal, 1(2), 91-113, 2008.

FREITAS, C. Rio de Janeiro: cidade modelo de sustentabilidade? Jornal do Brasil, 1 dez. 2013. Disponível em: <http://www.jb.com.br/rio/noticias/2013/12/01/rio-de-janeiro-cidade-modelo-desustentabilidade/>. Acesso em: 14 dez. 2016.

GIFE. Rio+B convida empresas para se engajarem em movimento pela sustentabilidade no Rio de Janeiro. GIFE website, 3 out. 2016. Disponível em: <http://gife.org.br/riob-convida-empresas-paramovimento-pela-sustentabilidade/>. Acesso em: $14 \mathrm{dez} .2016$.

JACOBI, P. Meio ambiente e sustentabilidade. In: JACOBI, P. O município no século XXI: cenários e perspectivas. São Paulo: Fundação Prefeito Faria Lima - Cepam, 1999, p. 175-183. 
JESUS, D. S. V.; KAMLOT, D. Economia criativa e políticas públicas. Curitiba: Prismas, 2016.

JOFFE, A. Cidades criativas ou bolsões criativos? Reflexões da África do Sul. In: REIS, A. C. F.; KAGEYAMA, P. (Orgs.). Cidades criativas: perspectivas. São Paulo: Garimpo de Soluções, 2011, p. 60-69.

LEITÃO, C. Políticas públicas para a economia criativa brasileira. In: REIS, A. C. F.; PASSOS, E.; BARRETO, L.; LEITÃO, C. Economia criativa e cidades criativas da Bahia: oficinas criativas. Salvador: Sebrae Bahia, 2013, p. 45-47.

MARCHI, L. Análise do Plano da Secretaria da Economia Criativa e as transformações na relação entre Estado e cultura no Brasil. Intercom - RBCC, 37 (1), 193-215, jan./jun. 2014.

MARQUES, P. Economia criativa. Jornal Opinião, 5 out. 2015. Disponível em: <http://www.jornalopiniao.net/editorias/geral/3643-economia-criativa>. Acesso em: 18 dez. 2015.

MAX-NEEF, M. Human scale development: conception, application and further reflections. New York: Apex Press, 1991.

MÉRCHER, L. Museu de Arte do Rio e Museu do Amanhã: duas ferramentas à paradiplomacia cultural do Rio de Janeiro. In: MONTEIRO, R. H.; ROCHA, C. (Orgs.). Anais do VI Seminário Nacional de Pesquisa em Arte e Cultura Visual. Goiânia: UFG, FAV, 2013, p. 101-111.

MIGUEZ, P. Economia criativa: uma discussão preliminar. In: NUSSBAUMER, G. M. (Org.). Teorias e políticas da cultura: visões multidisciplinares. Salvador: EDUFBA, 2007, p. 95-113.

MILES, S. A revitalização movida pela cultura funciona? In: GOLDENSTEIN, L.; ROSSELLÓ, P.; ARRUDA, F. (Coords.). Regeneração urbana através da cultura funciona? Londres, São Paulo: The British Council, 2014, p. 124-132.

MOURA, R. O turismo no projeto de internacionalização da imagem de Curitiba. Turismo - Visão e Ação, 9(3), 341-357, 2007.

RAGIN, C. Constructing social research: the unity and diversity of method. Thousand Oaks: Pine Forge Press, 1994.

RAPS. Plataforma de sustentabilidade para o Rio de Janeiro. RAPS website, 2016. Disponível em: <https://www.raps.org.br/site/wp-content/uploads/2016/07/2016-7-18_Plataforma-de-SustentabilidadeRio-de-Janeiro.pdf>. Acesso em: 14 dez. 2016.

REIS, A. C. F. Economia da cultura e desenvolvimento sustentável: o caleidoscópio da cultura. Barueri: Manole, 2006.

. Introdução. In: . (Org.). Economia criativa como estratégia de desenvolvimento: uma visão dos países em desenvolvimento. São Paulo: Itaú Cultural, 2008, p. 14-49. 
. Revelando o invisível: os enredados fios de ligação entre ícones culturais e os processos de transformação urbana. In: __ (Org.). Anais do Seminário Internacional Cultura e Transformação Urbana. São Paulo: Sesc Belenzinho, 22-23 nov. 2011, p. 10-14.

; URANI, A. Cidades criativas - Perspectivas brasileiras. In: REIS, A. C. F.; KAGEYAMA, P. (Orgs.). Cidades criativas: perspectivas. São Paulo: Garimpo de Soluções, 2011, p. 30-37.

SEBRAE. Termo de referência: atuação do sistema Sebrae na economia criativa. Brasília: Sebrae, 2012.

RIO CRIATIVO. Rio Criativo website. Disponível em: 〈http://riocriativo.com/incubadora/empresas〉.

ROMEIRO, A. R. Economia ou economia política da sustentabilidade? Texto para Discussão. IE/Unicamp, Campinas, n. 102, p. 1-28, set. 2001.

SACHS, I. Estratégias de transição para o século XXI: desenvolvimento e meio ambiente. São Paulo: Studio Nobel/Fundap, 1993.

SEC. Plano da Secretaria da Economia Criativa: políticas, diretrizes e ações, 2011-2014. Brasília: Ministério da Cultura, 2012.

SILVA, F. R. M. As relações entre cultura e desenvolvimento e a economia criativa: reflexões sobre a realidade brasileira. NAU Social, 3(4), 111-121, maio/out. 2012.

VAN EVERA, S. Guide to methods for students of political science. Ithaca, Londres: Cornell University Press, 1997.

WANIS, A. Cidade criativa: política urbana e cultural na reconstrução simbólica do Rio Olímpico. II Conferência Internacional Megaeventos e a Cidade. Rio de Janeiro, 27-30 abr. 2013. Disponível em: $<$ http://megaeventos.ettern.ippur.ufrj.br/sites/default/files/artigos-

cientificos/wanis_a._cidade_criativa.pdf $>$. Acesso em: 1 maio 2016.

WORLD CITIES CULTURE FORUM. Rio de Janeiro, 2015. Disponível em: <http://www.worldcitiescultureforum.com/cities/rio-de-janeiro>. Acesso em: 23 out. 2015.

Artigo recebido em 03/06/2017. Aceito para publicação em 21/08/2017. 